\title{
La expropiación indirecta frente al CIADI: consideraciones para la autorregulación de los actos administrativos de los Estados
}

\author{
Marisol Páez
}

En el ámbito de la expropiación hay gran controversia, no por la que transfiere el título de propiedad, sino por la expropiación indirecta. El problema radica en lo complejo que resulta la linea divisoria entre las medidas reguladoras legitimas y los actos que se consideran interferencias ilegitimas en los derechos e intereses de un inversionista extranjero y que dan como resultado una expropiación indirecta. Para comprender la expropiación indirecta en el derecho intemacional se analizan laudos arbitrales del CIADI, que es el foro más importante en el ámbito de la inversión avtranjera, se exponen los criterios comunes desarrollados's, por último, se dan a conocer algunos resguardos que deberian adoptar los Estados en la autorregulación de los actos administrativos relacionados con los inversionistas extranjeros.

\section{INTRODUCCIÓN}

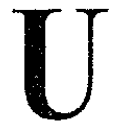

na de las áreas más controversiales en el derecho internacional es la expropiación de una inversión extranjera. Cumplidos los requisitos descritos por una determinada legislación y producida la transferencia del título de propiedad, estamos en presencia de una expropiación directa.

La discusión en torno a la expropiación se plantea cuando no existe transfe- rencia del título de propiedad. Es decir, cuando el Estado realiza una serie de actos que afectan el derecho de propiedad de una persona, pero esta conserva el título de propiedad. El problema es cómo determinar la línea divisoria entre medidas adoptadas legítimamente por los Estados de aquellas que se consideran interferencias ilegítimas en los derechos e intereses de los inversionistas extranjeros.

Algunas interferencias que se producen en los derechos de propiedad de un 
inversionista extranjero se conocen como expropiación indirecta. Brownlie definió esta como: «state measures, prima facie a lawful exercise of powers of governments, may' affect foreign interests considerably without amounting to expropriation. Thus, foreign assets and their use may be subjected to taxation, trade restrictions involving licenses and quotas, or measures of devaluation»!.

En los últimos treinta años la expropiación indirecta ha sido fuente de mucha discusión, lo que ha generado un rápido desarrollo. Ello ha sido principalmente evidente a partir de la jurisprudencia que resolvió las controversias sobre expropiación indirecta entre Estados Unidos e Irán.

\section{Han proliferado los tratados que regulan las inversiones extranjeras.}

Adicionalmente, los tratados que regulan las inversiones extranjeras han proliferado, al punto que hasta 2003 se habían suscrito más de 2.500 Acuerdos de Promoción y Protección de Inversiones $(\mathrm{APPI})^{2}$. La mayoría de ellos contempla la protección de inversiones cuando estas han sido objeto de actos expropiatorios, entre ellos actos que sean constitutivos de expropiación indirecta.

La finalidad de este artículo es lograr una mejor comprensión del concepto de expropiación indirecta de una inversión extranjera en el campo del derecho internacional. Para ello, se expondrán la evolución y la relación recíproca de las diversas fuentes del derecho internacional en materia de expropiación indirecta. En particular, mediante el análisis de laudos arbitrales del Centro Internacional de Arreglo de Disputas Relativas a Inversiones (CIADI) se presentarán los criterios que han desarrollado los tribunales arbitrales, formados al amparo de ese organismo, en materia de expropiación indirecta. Con ello, se busca lograr una guía para los Estados en la autorregulación de sus actos administrativos cuando estos sean aplicables a los inversionistas extranjeros.

\section{EXPROPIACIÓN INDIRECTA DE LA INVERSIÓN EXTRANJERA EN EL \\ DERECHO INTERNACIONAL}

Es importante precisar que solo se entenderán como actos o medidas de la administración del Estado las decisiones formales que emitan sus órganos y que contengan declaraciones de voluntad del Poder Ejecutivo realizadas en el ejercicio de una potestad pública. Este concepto restringido coincide con el reconocido por la legislación chilena ${ }^{3} y$ otras normativas

Brownlie, supra nota 1, pp. 509.

Disponible en <http://www.unctad.org/Templates/WebFlyer.asp?intItemID=3150\&lang=1>.

El artículo 3 de la Ley $N^{\circ} 19.880$, que establece las bases de los procedimientos administrativos que rigen los actos de los órganos de la Administración del Estado, define el acto administrativo como: «...Las decisiones formales que emitan los órganos de la Administración del Estado en las cuales contienen declaraciones de voluntad, realizadas en el ejercicio de una potestad pública... Constituyen, también, actos administrativos los dictámenes o declaraciones de juicio, constancia o conocimiento que realicen los órganos de la Administración en el ejercicio de sus competencias». 
europeas ${ }^{4}$. Sin embargo, hay tratadistas y normativas que le dan más amplitud al incluir además los actos dictados por órganos de los poderes judicial y legislativo ${ }^{5}$. Las razones para limitarlo son: primero, restringir el estudio y así lograr una mayor profundización en dicho ámbito y segundo, que las controversias en materia de expropiación planteadas ante tribunales internacionales se basan principalmente en actos provenientes del Poder Ejecutivo.

\subsection{El concepto de expropiación directa e indirecta ante el derecho internacional}

Un extranjero puede adquirir cualquier bien, tangible e intangible, siempre que se someta a la ley nacional del Estado en que lo adquiere. Sin embargo, ello no implica que en el ejercicio de su soberanía un Es- tado no pueda imponer ciertas restricciones a dicha adquisición ${ }^{6}$. El derecho internacional, a su vez, también protege el derecho de propiedad del extranjero ${ }^{7}$, pues a pesar de la soberanía que el Estado detenta, esta puede verse restringida, y más aún, puede constituirse en responsable de sus actos $u$ omisiones que impliquen una violación del derecho internacional. Así lo declaró la Corte Permanente de Justicia en el caso Chorzow al señalar, «it is a principle of international law, and even a general conception of law, that any breach of an engagement involves an obligation to make reparations.

Todo inversionista extranjero busca que los Estados no interfieran en sus intereses o derechos ${ }^{9}$. Asimismo, procura evitar problemas en el acceso al mercado, y en el establecimiento y protección de la inversión. Como contrapartida, los

4 Resolution (77) 31 On the Protection of the individual in relation to the acts of Administrative Authorities, adopted by the Committee of Ministres, Council of Europe: «administrative procedures with regard to any individual measures or decisions which are taken in the exercise of public authority and which are of such nature as directly to affect their rights, liberties or interests.»

5 NAFTA en el artículo 201 señala que es medida del Estado (término utilizado en el artículo 1110 que se refiere a la expropiación indirecta) «cualquier ley, reglamento, procedimiento, requisito o práctica».

6 En Chile, el Decreto Ley 1939 de 1977 prohibió la adquisición de terrenos fiscales situados a una distancia de hasta $10 \mathrm{~km}$ desde la frontera, los que solo pueden ser adquiridos en propiedad, arrendamiento o a cualquier otro titulo por personas naturales o juridicas chilenas. Igual norma se aplica respecto de terrenos fronterizos (dominio, otros derechos reales, posesión o tenencia) que no pueden ser adquiridos por nacionales de paises limítrofes por razones de interés nacional.

7 En CIADI, Amco Asia Corp., Pan American Development Ltd., y P.T. Amco Indonesia v. República de Indonesia, CIADI Caso No. ARB/81/1, el tribunal consideró «es una norma generalmente aceptada de Derecho Internacional, claramente establecida en sentencias y laudos internacionales y generalmente aceptada en la doctrina que un Estado tiene el deber de proteger a los extranjeros y a sus inversionistas frente a actos ilegales cometidos por algunos de sus ciudadanos...Si tales actos son cometidos con la asistencia activa de órganos del Estado tiene lugar una violación de Derecho Internacional». En el Artículo 13, el Energy Charter Treaty de 1994, establece que: «investments of investors of a Contracting Party in the Area of any other Contracting Party shall not be nationalized, expropriated or subjected to a measure or measures having effect equivalent to nationalization or expropriation».

8 Chorzow Factory (get v. Pol.), 1927 P.C.I.J., ser. A, No.7. Par. 29.

9 Lowe, Vaughan, supra nota 9, p. 447. 
Estados buscan incentivar el crecimiento económico mediante la inversión extranjera. En este escenario, los Acuerdos de Promoción y Protección de Inversiones (APPI) y las disposiciones sobre inversiones de los Tratados de Libre Comercio (TLC) han desarrollado una buena vía de protección a través de la regulación del tratamiento de la inversión extranjera, ofreciéndole al inversionista, una serie de garantías sustantivas y procesales.

\section{Los inversionistas extranjeros buscan que los Estados no interfieran en sus intereses 0 derechos.}

Estas garantías apuntan a disminuir al inversionista la incertidumbre y el factor riesgo que suelen acompañar a una inversión extranjera, dándoles mediante estos acuerdos un marco regulatorio básico que le ofrezca un nivel mínimo de seguridad jurídica, como son las garantías derechos y obligaciones básicos.

Una de las consideraciones importantes que debería tener un extranjero para invertir en un país es su protección en caso de que sea afectado por una expropiación. Al respecto, un concepto estricto de expropiación se refiere a la transferencia directa del título de propiedad ${ }^{10}$, que comprende la nacionalización de toda la propiedad privada respecto de una producción; la nacionalización de una industria determinada para crear un monopolio del Estado; la expropiación en gran escala cuando hay toma de terrenos y su distribución en la población no propietaria; $y$ las expropiaciones particulares de un terreno determinado"

Además de la expropiación propiamente tal o directa el derecho internacional distingue la expropiación indirecta. Esta última comprende, aquella en que el inversionista conserva el título legal de la propiedad pero ve limitados sus derechos de uso de la propiedad como consecuencia de una interferencia del Estado ${ }^{12}$. Esta

Madalena, Ignacio, «Foreign Direct Investment and the Protection of the environment: the Border Between National Environmental Regulation and Expropriation», European Environmental Law Review, Vol. 12. No 3, 2003, p. 72. En el contexto del derecho internacional, propiedad se refiere a la propiedad de bienes tangibles e intangibles. El Tribunal que resolvió las controversias entre IranEstados Unidos señaló en el caso Starret Housing Corp. v. Islamic Republic of Iran: «[the claimants] rely on precedents in international law in which case measures of expropriation or takings, primarily aimed at physical property, have been deemed to comprise also rights of a contractual nature closely related to the physical property...». Asimismo, en el Protocolo 1 de la Convención Europea de Derechos Humanos, el concepto de propiedad es definido haciendo referencia a todos los intereses del propietario: «movable or immovable property, tangible and intangible interests, such as shares, patents, an arbitration Laudo, the entitlement to a pension, a landlord's entitlement to rent, the economic interests connected with the running of a business and the right to exercise a profession...). Madalena, Ignacio, supra nota 10, p. 72.

12 Starret Housing Corp. v. Iran, stupra nota 12. Par. 1117. «It is undisputed in this case that the Government of Iran did not issue any law or decree according to which the Zomorod Project or Shah Goli expressly was nationalized or expropriated. However, it is recognized in international law that measures taken by a state can interfere with property rights to such an extent that these rights are 
puede producirse cuando ejerce su «poder de policía», es decir, aquellas medidas adoptadas por el Estado relativas a la aplicación de regulaciones del medio ambiente, la salud, la moral, la cultura o la economía de un país ${ }^{13}$.

\section{Hay expropiación indirecta cuando el inversionista conserva el título de la propiedad pero el Estado interfiere en su uso.}

El derecho internacional ha protegido de expropiación la propiedad de los extranjeros, dándole a su dueño el derecho a indemnización por el valor de la propiedad perdida ${ }^{14}$. Es claro, el pago compensatorio en caso que la expropiación implique transferencia de propiedad. En el mismo sentido el profesor Orrego sostuvo: «It was only after difficult confiontations that an understanding was reached about the limits of the respective contentions and that conditions were set ...the right to expropriate, including the right to compensation $)^{15}$. La pregunta que surge es cómo distinguir entre una medida regulatoria y una interferencia ilegítima en los derechos e intereses de un inversionista extranjero.

La costumbre internacional no reconoce el pago compensatorio por una expropiación cuando el fundamento invocado por el Estado sea el ejercicio de su poder de policía o utilidad pública ${ }^{16}$. No obstante, actualmente la mayoría de los acuerdos sobre inversión contemplan el pago compensatorio por la expropiación de una inversión extranjera. Estos acuerdos precisan los términos y condiciones de una expropiación señalando que ella debe reunir cuatro requisitos: a) utilidad pública; b) no discriminación; c) indemni-

rendered so useless that they must be deemed to have been expropriated...». Tratado Francia-USSR de 1989, artículo 4: «Investments shall not be expropriated or nationalized either directly or indirectly though measures tantamount to expropriation or nationalization except...). Gate University, Law Review, Vol. 29, 1999, p. 465. El artículo 11 10(1) del NAFTA establece que: «Ninguna de las Partes podrá nacionalizar ni expropiar, directa o indirectamente, una inversión de un inversionista de otra Parte en su territorio, ni adoptar ninguna medida equivalente a la expropiación o nacionalización de esa inversión (expropiación), salvo que sea: a. por causa de utilidad pública; $b$. sobre bases no discriminatorias; c. con apego al principio de legalidad y al Artículo 1105(1); y d. mediante indemnización conforme a los párrafos 2 a 6.

Orrego Vicuña, Francisco, «Carlos Calvo, Honorary Nafta Citizen», N.Y.U. Environmental Law Journal, Vol. 11, 2002, p. 20.

16 El artículo 2 de la Carta de Derechos y Obligaciones Económicas de los Estados establece que: «Each State has the right: c) to nationalize, expropriate or transfer ownership of foreign property in which case appropriate compensation should be paid by the State adopting such measures, taking into account its relevant laws and regulations and all circumstances that the State considers pertinent», Brownlie, supra nota 1, 508, concluye que: «Assuming that the provisions of article 2 are to be reckoned with, as evidence of new customary law, what are the consequences? The concept of permanent sovereignty over natural resources reinforces the existing principle that taking for public purposes is lawful». 
zación y; d) necesidad de un debido proceso ${ }^{17}$. Sin embargo, pese a este avance, las controversias ante tribunales internacionales sobre expropiación siguen presentes, según lo revela el informe anual de 2004 del CIADI, que concluye que las disputas han aumentado un $15 \%{ }^{18}$. La determinación de si un acto de la administración del Estado equivale a expropiación es una de las cuestiones fundamentales de un buen número de demandas interpuestas por inversionistas extranjeros ante tribunales arbitrales ${ }^{19}$. En consecuencia, al momento de determinar la responsabilidad de un Estado, el alcance del concepto de expropiación indirecta es importante debido al impacto de los actos de la Administración en la propiedad de nacionales de otros Estados.

\section{Las controversias sobre expropiación indirecta de inversiones extranjeras datan de la década de 1920.}

\subsection{Evolución de la expropiación indirecta en la legislación internacional}

Las disputas entre inversionistas extranjeros (por proteger sus activos) y los Estados (por proteger su autoridad soberana) no son un tema reciente. Ya en la década de 1920, surgieron controversias sobre expropiación indirecta de inversiones extranjeras ${ }^{20}$. Los tribunales internacionales resolvieron dichos casos basándose en la costumbre internacional. Sin embargo, los instrumentos internacionales que se refieren a la expropiación indirecta solo se suscribieron a partir de los años cincuenta $^{21}$. Después de la Segunda Guerra Mundial, países en desarrollo y Estados de la órbita socialista adoptaron medidas legales y económicas destinadas a transferir la propiedad de extranjeros a manos del Estado o de grupos nacionales. En respuesta a estos sucesos, algunos

17 UNCTAD Series, nota 13 sipra p. 24. Algunos ejemplos son: APPI de Egipto y Grecia de 1993, articulo 4: «Investments by investors of either Contracting Party shall not be expropriated, nationalized or subjected to any other measure the effects of which would be tantamount to expropriation or nationalization in the territory of the other Contracting Party except under the following conditions: a) the measures are taken in the public interest and under due process of law, b) the measures are clear and not discriminatory, and c) the measures are accompanied by provisions for the payment of prompt, adequate and effective compensation.» El artículo III del APPI entre Estados Unidos y Ucrania de 1994, dice: «1. Investments shall not be expropriated or nationalized either directly or indirectly through measures tantamount to expropriation or nationalization (expropriation) except: for a public purpose; in a nondiscriminatory manner; upon payment of prompt, adequate and effective compensation; and in accordance with due process of law and the general principles of treatment...».

Disponible en <http://www.worldbank.org/CIADI/pubs/1998ar/2004_CIADI_ar_sp.pdf>. United Sates Foreign Claims Settlement Commission, Iran-United States Claims Tribunal, The European Commission on Human Rights and the European Court of Human Rights. El primer APPI fue suscrito entre Alemania y Pakistán en 1959 y a su vez, el origen de los APPI se atribuye a los Tratados de Amistad, Comercio y Navegación. 
estados en conjunto o individualmente decidieron proteger la propiedad de sus inversionistas en el extranjero contra las expropiaciones indirectas ${ }^{22}$.

\section{Para elevar los estándares de liberalización y protección de la inversión la OCDE propició un tratado multilateral de inversión.}

En 1961, la Harvard Draft Convention on the International Responsibility of States for Injuries to Aliens, incluyó la prohibición de la expropiación indirecta reconociéndose por primera vez en su artículo 10(3)(a) el principio de interferencia no razonable en el uso de la propiedad priva$\mathrm{da}^{23}$ : «taking of property includes not only an outright taking of property but also any such unreasonable interference with the use, enjoyment, or disposal of property as to justify an inference that the owner thereof will not be able to use, enjoy, or dispose of the property within a reasonable period of time after the inception of such interferences.

En 1967, el artículo $3^{24}$ de la Draft Convention on Protection of Foreign Property, de la OCDE, señaló más clara- mente la expropiación indirecta al disponer: «no Party shall take any measures depriving, directly or indirectly, of his property a national of another Party...».

Posteriormente, en 1992, el Comité para el Desarrollo del Banco Mundial elaboró «Guidelines on the Treatment of Direct Investment», que es una guía para los Estados en materia de admisión y tratamiento de las inversiones extranjeras en sus territorios. En su artículo IV (1) sobre Expropriation and Unilateral Alterations or Termination of Contracts dispone: «A state may not expropriate or otherwise take in whole or in part a foreign private investment in its territory, or take measures which have similar effects, except where this is done in accordance with applicable legal procedures, in pursuance in good faith of a public purpose, without discrimination on the basis of nationality and against the payment of appropriate compensation».

Entre 1995 y 1997, en un intento por elevar los estándares de liberalización y protección a la inversión, la OCDE promovió un tratado multilateral de inversión ${ }^{25}$ aún no aprobado, cuyo artículo 2 incluye la expropiación indirecta: «A Contracting Party shall not expropriate or nationaPurposes», Fortun du droit International, Vol. 5, № 3, 2003, p. 169.

23 económicas y sociales.

Comentarios del Grupo de Expertos al texto del Tratado Multilateral de Inversión, de 24 de abril de 1998. Disponible en <http://www.oecd.org/dataoecd/37/27/2758531.pdf>. 
lise directly or indirectly an investment in its territory of an investor of another Contracting Party or take any measure or measures having equivalent effect (hereinafter referred to as uexpropriation») except: a) for a purpose which is in the public interest, b) on a nondiscriminatory basis, c) in accordance with due process of law, and d) accompanied by payment of prompt, adequate and effective compensation.... ${ }^{26}$.

Por último, la mayoría de los Acuerdos de Promoción y Protección de Inversiones (APPI o BIT) y los Capítulos sobre Inversiones de los Tratados de Libre Comercio (TLC) contienen disposiciones uniformes relativas al objetivo de la aplicación del tratado, acceso al mercado, establecimiento y protección a la inversión y, por último, el mecanismo de solución de controversias ${ }^{27}$. Los APPI no solo protegen al inversionista extranjero de la expropiación directa, sino que han incorporado cláusulas que protegen los intereses de los inversionistas extranjeros de aquellos actos que sean considerados expropiación indirecta. Claúsulas usuales son: «medidas de expropiación o nacionalización o cualquier otra medida que provoque directa o indirectamente la pérdida de la posesión», «teniendo el efecto equi- valente a nacionalización o expropiación», «cualquier medida directa o indirecta»o «cualquier otra medida que tenga la misma naturaleza o efecto contra la inversión $\rangle^{28}$.

\subsection{Evolución de la expropiación indi-} recta en la jurisprudencia intemacional

De acuerdo con lo dispuesto en el artículo 38(1)(d) del Estatuto de la Corte Internacional de Justicia una de las fuentes del derecho internacional son «...las decisiones judiciales... como medio auxiliar para la determinación de las reglas de derecho.... $\rangle^{29}$. En consecuencia, la labor desempeñada por tribunales sean estos internacionales o nacionales, institucionales o ad-hoc es fundamental para conocer mejor la doctrina de la expropiación indirecta. A continuación se presentarán las más relevantes decisiones de tribunales internacionales.

\section{En Norwegian Shipowners se discutió la indemnización que debía pagar Estados Unidos por contratos de construcción de buques en astilleros noruegos.}




\section{Se observó la tendencia a proteger los derechos incorporales como propósito del derecho constitucional.}

En 1922 se produjo la controversia conocida como Norwegian Shipowners ${ }^{30}$, que versó sobre el monto de la indemnización que debía pagarse a los dueños de astilleros noruegos que tenían contratos de construcción de barcos con firmas estadounidenses. Cuando Estados Unidos entró en la Primera Guerra Mundial, requisó barcos en construcción, materiales y equipamiento. Los dueños de los astilleros noruegos alegaron ante la Corte Permanente de Arbitraje que la indemnización debía incluir, además del valor de los barcos requisados, el pago por los contratos de construcción, que no podrían cumplir. Por su parte, Estados Unidos sostuvo que lo requisado era solo parte de los barcos en construcción y no los contratos por lo cual la indemnización no podía incluirlos y argumentó que, de acuerdo con el derecho internacional, los derechos contractuales no eran derechos de propiedad. La Corte falló en favor de los noruegos, señalando que se había producido una expropiación de facto y que la indemnización debía ser de acuerdo con un justo valor de mercado. Pese a que el tribunal no estableció lo que constituía expropiación indirecta, precisó qué actos del go- bierno afectaban el derecho de propiedad, al señalar que: «(United States) took over the legal rights and duties of the shipowners towards the shipbuildersy ${ }^{3 !}$.

Un segundo caso, importante fue el de la fábrica de Chorzow, en el cual la controversia se centró en determinar si la indemnización por expropiación incluía el pago por contratos y patentes comerciales. En 1926, el gobierno polaco expropió una fábrica de Oberschlesische, compañía alemana administrada por Bayerische, otra empresa alemana, situada en la localidad de Chorzow. El contrato de administración de Bayerische incluía patentes $y$ contratos comerciales. La Corte Permanente de Justicia Internacional consideró que en el caso de Bayerische había expropiación indirecta. Aunque el gobiemo polaco argumentó que el propósito de la expropiación no eran esos aspectos particulares de la propiedad, el tribunal señaló «it is clear that the rights of the Bayerische to the exploitation of the factory and to remuneration fixed by the contract... have been directly prejudiced by the taking over of the factory by $\mathrm{PO}$ land $\rangle^{32}$.

En los dos casos anteriores es importante hacer hincapié, primero, en que la interferencia en la propiedad constituye expropiación, «even though a State may not purport to interfere with rights to property' ${ }^{33}$, y segundo, en la tendencia a

30 Norwegian Shipowners Claims (Nor. v. U.S.), 1 R. Int'l Arb. 1922. Laudo 307.

31 Norwegian Shipowners Claims, supra note 30.

32 Chorzow, nota 8 supra Par. 44.

33 Christie, G. C., «What Constitutes a Taking of Property Under International Law?», British Yearbook of International Law, Vol. 38, 1962, p. 311. 
proteger los derechos incorporales como propósito del derecho constitucional, que tradicionalmente solo incluía los derechos corporales en el concepto de propiedad ${ }^{34}$.

\section{La CIJ falló que los accionistas no podían reclamar por perjuicios sufridos por expropiación indirecta.}

En el caso de Oscar Chinn, de 1934, la controversia entre Bélgica y el Reino Unido versó sobre si la pérdida de competitividad de un negocio debido a la adopción de una medida gubernamental constituía o no expropiación indirecta. Un naviero británico debió poner fin a su negocio de transporte desde el Congo debido a que el gobierno belga, que era dueño de la mayoría de las acciones de su único competidor, Unatra, otorgó subsidios a esta y redujo el valor de los fletes por un período determinado, a fin de favorecer la economía del Congo. La Corte Permanente consideró que la pérdida de utilidades se había debido a la situación económica general y no a las medidas adoptadas por el gobierno belga, no aceptando los argumentos esgrimidos por el Reino Unido referidos a que Bélgica era responsable de las pérdidas del señor Chinn. Concluyó que no hubo expropiación señalando «favorable business conditions and good-will are transient circunstances, subject to inevitable changes $\rangle^{35}$.
Otro caso es el de la Barcelona Traction $^{36}$, en 1970, que fue el primero relativo a expropiación indirecta conocido por la Corte Internacional de Justicia. Las alegaciones hechas por Bélgica contra España se centraron en la indemnización que correspondía a los accionistas belgas de la sociedad canadiense Barcelona Traction, debido a que España no permitía transferir dinero al extranjero para cumplir con el pago de bonos. A consecuencia de ello, la Barcelona Traction quebró. El gobierno canadiense rehusó hacer uso de su derecho a protección diplomática en favor de los accionistas belgas. Bélgica presentó una demanda por los perjuicios sufridos por los accionistas belgas. Sin embargo, la Corte rechazó la demanda por falta de locus standi, pues consideró que las pérdidas eran de la compañía y no de los accionistas. Según la Corte, de acuerdo con la costumbre internacional los accionistas de sociedad inversionista extranjera no tenían derecho a reclamar por perjuicios sufridos por expropiación indirecta y solo podía hacerlo la sociedad.

Dos razones explican la importancia de este caso: la primera es que dos jueces con opiniones disidentes consideraron que si existía expropiación indirecta, y la segunda, que la decisión señaló que el derecho internacional protege a las empresas como personas jurídicas independientes de sus accionistas, lo cual implica que en ausencia de APPI o MAI, el derecho inter-

34 Dolzer, Rudolf, «Indirect Expropriation of Alien Property», Foreign Investment Law Journal, Vol. 1, $N^{0} 1,1986$, p. 42. 
nacional no protege a los accionistas de la expropiación $^{37}$.

Cabe preguntarse si la jurisprudencia ha sido concordante con los argumentos invocados en los casos de expropiación indirecta.

Hay nutrida jurisprudencia sobre expropiación en las disputas entre Estados Unidos de América e Irán, a raíz de las políticas económicas aplicadas por el gobierno revolucionario iraní a partir de 1979. De las cerca de sesenta decisiones sobre expropiación, la mayoría son por expropiación indirecta ${ }^{38}$. Las principales alegaciones se basaron en la determinación de la procedencia de indemnización, la atribución de actos expropiatorios a acciones del Estado, el monto de la indemnización y la valoración de la propiedad ${ }^{39}$.

Entre los numerosos casos se han elegido dos como representativos de las disputas planteadas ante el tribunal ${ }^{40}$. El caso Starrett Housing ${ }^{41}$ fue el primero conocido por el Iran-United States Claims Tribunal, que se refirió al nombramiento de gerentes iraníes en un proyecto habita- cional estadounidense. El tribunal concluyó que una expropiación se produce cuando: "It is recognised by international law that measures taken by a State can interfere with property rights to such an extent that these rights are rendered so useless that they must be deemed to have been expropriated, even though the State does not purport to have expropriated them and the legal title to the property formally remains with the original owner»y.

En el segundo caso, Sea-Land ${ }^{42}$, uno de los objetos de la controversia fue la expropiación de una cuenta bancaria. El tribunal, contrariamente a lo resuelto en otros fallos no consideró que hubiese expropiación señalando: «finding of expropriation would require, at the very least, that the Tribunal be satisfied that there was deliberate governmental interference with the conduct of Sea-Land's operation, the effect of which was to deprive Sea-Land of the use and benefit of its investment. Nothing has been demonstrated here which might have amounted to an intentional course of conduct directed against Sea-Land. A claim founded substantially on

37 Khalaf Masa'Deh, Ahmad, nota 27 supra, p. 160.

38 Heiskanen, Veijo, «The Contribution of the Iran-United States Claims Tribunal to the Development of the Doctrine of Indirect Expropriation", International Law Fortum, Vol. 5, № 3, 2003, p. 178.

39 Brunetti, Maurizio, «Indirect Expropriation in International Law. Recurring Themes», International Law Fortum du droit international, Vol. 5, 2003, p. 153.

40 Para acceder a mayor detalle de los casos conocidos por el tribunal, ver Mouri, Allahyar, The International Law of Expropriation as Reflected in the Work of the Iran-U.S. Claims Tribunal, Dordrecht, Martinus Nijhoff Publishers, 1994. Piran, Hossein, «Indirect Expropriation in the Case Law of the Iran-United States Claims Tribunal», The Finnish Yearbook of International Law, Vol. 6. 1995, pp. 140-247 y Brunetti, Maurizio, nota 39 sipra, pp. 150-154.

4 Starret Housing Corp. v. Iran, nota 12 supra.

42 Sea-Land Service Inc. v. Iran, 6 Cl. Trib. Rep.149 (1984). See Seddigh and Aldrich p. 656, op. cit. 31. 
omissions and inaction in a situation where the evidence suggests a widespread and indiscriminate deterioration in management, distupting the functioning of the port of Bandar Abbas, can hardly justify a finding of expropriations.

A modo de conclusión de esta sección sobre la evolución del concepto de expropiación indirecta, puede señalarse que existen distintas tendencias en cuanto a si la jurisprudencia ha sido concordante con los argumentos invocados en los casos de expropiación indirecta. La mayoría de los autores, como Dolzer, Wagner y Weiner, sostienen que las resoluciones de los tribunales internacionales son impredecibles y deben verse caso por caso. Dolzer sostiene, "international takings doctrine is in disarray, the jurisprudence is inconsistent, and the result is often unpredictable» ${ }^{43}$. Wagner concluye "International tribunals have not agreed on a definitive test establishing when indirect expropriation gives rise to a right to compensation ${ }^{\text {t4 }}$. Weiner, por su parte, señala que, «indirect expropriation jurisprudence and state practice reveal competing doctrinal strains, some that tend to favor the interests of foreign property owners, and other that the favor the regulatory authority of states $\rangle^{45}$.
1.4. Actos de la administración del Estado que constituyen expropiación indirecta de acuerdo con el derecho internacional

A continuación se presentan los actos de la administración del Estado que según la jurisprudencia, los tratadistas y la normativa internacional pueden considerarse expropiación indirecta.

Se considera acto expropiatorio a la privación de la propiedad 0 uso legítimo de bienes intangibles.

1.4.1. La expropiación de bienes intangibles

Se considera que hay acto expropiatorio cuando el dueño es privado de la propiedad o del uso legítimo de bienes intangibles, tales como patentes y contratos comerciales. Las condiciones necesarias para que se considere expropiación indirecta es que la privación no sea transitoria. Así lo confirmaron la Corte Permanente de Arbitraje y la Corte Permanente de Justicia Internacional en los casos Norwegian Ownerships y Chorzow.

\subsubsection{La expropiación de inmuebles}

Un propietario puede verse limitado en el uso y goce de un inmueble pese a que conserva el título de dominio. En el

43 Dolzer, Rudolf, nota 34 supra, p. 42

44 Wagner, J. Martin, nota 14 stipra, p. 520.

45 Weiner, Allen S., nota 22 supra, p. 169. 
caso Malek, entre Estados Unidos de América e Irán, el tribunal señaló que: "According to Tribunal precedent, an interference with the use of a property may amount to a taking if such interference is considered unreasonable. Such is deemed to be the case when the events demonstrate that the owner was deprived of fundamental rights of ownership and it appears that this deprivation is not merely ephemeraly ${ }^{46}$.

\subsubsection{Transacciones forzadas}

Son actos expropiatorios cuando la autoridad de un Estado obliga al dueño de una propiedad a suscribir una transacción. EI Profesor Christie señala que: "Where a State compels an alien to sell his property for less than its true value either to the State or to a third party, a compensable claim arises ${ }^{47}$. Siguiendo este mismo razonamiento, el tribunal del caso American Bell entre Estados Unidos e Irán sostuvo: "Where, as here, both the prose and effect of the acts are totally to deprive one of funds without one's voluntary' given consent, the finding of a compensable taking under any applicable law, international or domestic, is inevitable, unless there is clear justification for the seizure» ${ }^{48}$. Sin embargo, no puede considerarse que exista expropiación en una transacción forza- da cuando el precio de la venta de una propiedad es bajo por el temor a una posible expropiación. Así lo concluyó el tribunal en el caso Emanuel Too: «A State is not responsible for loss of property or for other economic disadvantage resulting from bona fide general taxation or any other action that is commonly' accepted as within the police power of States, provided it is not discriminatory and is not designed to calse the alien to abandon the property to State or to sell it at a distress price» ${ }^{49}$.

1.4.4. Rechazo a devolver la propiedad

Cuando una propiedad está bajo el control del Estado y este, sin justificación aparente, no está dispuesto a devolverla, la propiedad puede considerarse expropiada y el dueño tiene derecho a una indemnización por su valor total ${ }^{50}$. Así lo dispone tribunal en el caso Irán v. Estados Unidos de Norteamérica: "Iran, therefore has been completely deprived of its property by the conduct of the United States, even if the United States never expressed its intention to appropriate this property and never attempted to dispose of it without Iran's authorization. Such deprivation, undoubtedly, entails for Iran prejudicial consequences similar to those which would have been the result of an expropriation. Under International Law the State

46 Reza Said Malek v. The Government of the Islamic Republic of Iran, Laudo No 534-193-3 de 1992.

48 American Bell International Inc. v. Iran et al., Laudo $N^{\circ} 255-48-3$ de 1986.

49 Emanuel Too v. Greater Modesto Insurance Associates et al., Laudo No 460-880-2 de 1989.

so

Christie, G. C., nota 33 supra, p. 337. 
responsible for such deprivation is liables ${ }^{51}$.

\subsubsection{Imposición en el control} gerencial de la propiedad: designación de gerentes e interferencia en el derecho a administrar

El nombramiento transitorio de gerentes para la administración de compañías cuyos dueños son extranjeros es una privación del derecho de propiedad que constituye un acto expropiatorio. En el caso Tippetts entre Estados Unidos de América e Irán el tribunal consideró que: «While assumption of control over property by a government does not automatically an immediately justify a conclusion that the property has been taken by the government, thus requiring compensation under international law, such conclusion is warranted wherever events demonstrate that the owner was deprived of fundamental rights of ownership and it appears that this deprivation is not merely ephemeraly ${ }^{\text {s2 }}$.

El nombramiento de gerentes para administrar empresas de dueño extranjero se considera acto expropiatorio.

A pesar de lo señalado anteriormente, la jurisprudencia no ha sido uniforme al respecto. Tribunales tales como la United States Foreign Claims Commission o el tribunal constituido para resolver las controversias de Europa del Este en el período posterior a la Primera Guerra Mundial, han considerado que la interferencia en la gestión de administrar no constituye expropiación indirecta. Tras analizar de estas últimas controversias Weston concluyó que: «No strictly international tribunal apparently ever having addressed these cases directly, one is left to look at the available decisions of domestic tribunals. Four cases decided by Dutch tribunals in the late 1930 s... each result from de appointment of a public administrator for a private firm in Nazi controlled territory... despite differences... appear to say that compulsory administration for a private wealth by public authorities does not alone constitute a compensable event... This conclusion seems confirmed by the only other leading National Socialist «State Administration» case so far decided $\aleph^{53}$.

\subsubsection{Prohibición de transferir fondos} o bienes fuera del país

La imposibilidad de transferencias de productos por extranjeros solo excepcionalmente es un acto expropiatorio. Será expropiación indirecta únicamente cuando se compruebe que el propietario hizo todo lo posible para la exportación del bien

51 República Islámica de Iran v. Estados Unidos, Laudo Parcial Nº 382-B1-FT de 1988. creeping expropriation», 16 Virginia JIL (1975-76), pp. 337-338. 
y que vio frustrada su operación por un acto discriminatorio del gobierno. En el caso Houston Contracting Company entre Iran y Estados Unidos, el Tribunal rechazó la demanda argumentando: "HCC(Houston Contracting Company) is required to show that it took all reasonable steps to export the equipment, so as to satisfy, the burden of proof to show that the losses suffered by it were incurred as a result of act or omission of Iran and not by HCC's own failure to acts $^{54}$.

\section{Solo hay expropiación indirecta}

\section{cuando el dueño no pudo exportar un producto por acto discriminatorio del gobierno.}

El hecho de que la prohibición de transferir dineros al extranjero sea acto constitutivo de expropiación indirecta no es tan clara, pues regulaciones del Fondo Monetario Internacional permiten que los Estados miembros limiten la transferencia de capitales ${ }^{55}$. Para dar mayor seguri- dad a los inversionistas extranjeros, la mayoría de los tratados sobre inversiones ${ }^{56}$ contemplan el deber de los Estados de garantizar a los inversionistas la libre transferencia de su inversión y dividendos ${ }^{57}$.

\subsection{El Centro Internacional de} Arreglo de Diferencias Relativas a Inversiones (CIADI) como vía solución de controversias relativas a expropiación indirecta

La expropiación indirecta surge como tema de estudio relevante debido a la constante presión a que se ven sometidos los gobiernos por proteger su industria nacional, el medio ambiente y la salud ${ }^{58}$. Por su parte, los inversionistas extranjeros buscan que los Estados receptores del capital no interfieran en sus derechos e intereses ${ }^{59}$. Para solucionar los conflictos que se producen entre inversionistas extranjeros y Estados receptores de capital, en 1965 con la suscripción del Tratado de Washington, se creó el Centro Internacional de Arreglo de Diferencias Relativas a

Houston Contracting Company v. National Iranian Oil Company et al. Laudo $N^{0} 378-173-3$ de 1988.

Convenio Constitutivo del Fondo Monetario Internacional, artículo XIV, sección 2. Disponible en <http://www.inf.org/external/pubs/ft/aa/spa/aa06.htm>.

Artículo $10.8 \mathrm{~N}^{\circ} 1$ del TLC Chile-Estados Unidos: «Each Party shall permit all transfers relating to a covered investment to be made freely and without delay into and out of its territory. Such transfers include: (a) contributions to capital; (b) profits, dividends, interest, capital gains, royalty payments, management fees, and technical assistance and other fees...»; del BIT-Turquía, y el articulo IV: «Each Party shall permit all transfers related to an investment to be made freely and without delay into and out of its territory. Such transfers include: (a) returns; (b) compensation pursuant to Article III; (c) payments arising out of an investment dispute; (d) principal and interest payments arising under loan agreements, and; (e) proceeds from the sale or liquidation of all or any part of an investment».

$<$ hhttp://www.worldbank.org/CIADI/news/n-17-2-5.htm>.

Dolzer, Rudolf, nota 34 supra, p. 66.

Lowe, Vaughan, nota 9 supra, p. 447. 
Inversiones (CIADI), uno de los principales foros de solución de controversias sobre inversión extranjera. El CIADI es una organización internacional autónoma aunque mantiene vínculos muy estrechos con el Banco Mundial. El CIADI se compone de un Consejo Administrativo y una Secretaría; asimismo, mantiene un listado permanente de conciliadores y de árbitros. Su objetivo es contribuir a promover la inversión extranjera al proporcionar servicios internacionales de conciliación y arbitraje en diferencias relativas a inversiones $^{60}$.

\section{El CLADI es una organización autónoma que mantiene vínculos estrechos con el Banco Mundial.}

El ámbito de jurisdicción del CIADI, es limitado pues para que un tribunal arbitral pueda conocer de una controversia deben reunirse tres requisitos: a) Consentimiento de ambas partes; b) Ratione materiae, la controversia debe surgir directamente de una inversión; c) Ratione personae, una de las partes debe ser un Estado contratante del CIADI y la otra un nacional (ente privado) de otro Estado contratante ${ }^{61}$.

Los Estados contratantes y los nacionales de otros Estados no contratantes del
Convenio que, por consiguiente, no tienen acceso a la jurisdicción del CIADI, pueden acceder a él a través de un mecanismo complementario en virtud del cual la Secretaría del CIADI puede administrar procedimientos que originalmente están fuera de su ámbito de jurisdicción.

Desde su creación en 1965 hasta la publicación del informe anual de 2004, el CIADI ha registrado $159 \operatorname{casos}^{62}$. Las demandas más recurrentes en la actualidad son sobre expropiación o denegación de justicia ${ }^{63}$. En particular, las controversias sobre expropiación directa han sido reemplazadas por disputas relacionadas con la reglamentación de la inversión extranjera y la expropiación indirecta ${ }^{64}$.

De lo anterior se desprende la importancia de estudiar y examinar laudos pronunciados por tribunales arbitrales del CIADI, en materias relativas a expropiación indirecta y buscar criterios comunes en dicho ámbito.

\section{EXPROPIACIÓN INDIRECTA EN LAUDOS ARBITRALES DEL CIADI}

El objetivo de este estudio fue determinar si existen criterios uniformes en las decisiones tomadas por los tribunales arbitrales del CIADI en materia de expropiación indirecta. Conjuntamente con
60

Disponible en <http://www.worldbank.org/CIADI/about/about.htm>.

Véase Convenio de Washington en <http://www.worldbank.org/CIADI/basicdoc/basicdoc.htm>.

Disponible en <http://www.worldbank.org/CIADI/pubs/1998ar/2004_CIADI_ar_sp.pdf>.

Disponible en <http://www.worldbank.org/CIADI/cases/main.htm>.

Yannaca-Small, Catherine, «Indirect Expropriation» and «The Right to Regulate» en International Investment Law, Organisation for Economic Co-operation and Development, No 4, 2004, pp. 1-22. Tradex Hellas S.A. v. República de Albania. CIADI Caso No. ARB/94/2. Laudo, 29 de abril de 1999. 
la legislación internacional, la jurisprudencia de otros tribunales y la doctrina disponible en materia de expropiación indirecta se analizaron los siguientes laudos arbitrales del CIADI: Tradex Hellas S.A. v. República de Albania ${ }^{65}$, Robert Azinian, Kenneth Davitian y Ellen Baca v. Los Estados Unidos Mexicanos ${ }^{66}$, Compañía del Desarrollo de Santa Elena S.A. v. Republic of Costa Rica ${ }^{67}$, Metalclad Corporation v. Los Estados Unidos Mexi$\operatorname{canos}^{68}$, Eudoro Armando Olguín v. República de Paraguay ${ }^{69}$, Middle East Cement Shipping and Handling Co. SA v. República de Egipto ${ }^{70}$, Marvin Feldman v. Los Estados Unidos Mexicanos ${ }^{71}$, Ténicas Medioambientales Tecmed S.A. v. Los Estados Unidos Mexicanos ${ }^{72}$, Generation Ukraine, Inc v. Ukrania ${ }^{73}$, Waste Management, Inc. v. Los Estados Unidos Mexicanos $^{74}$.

\section{Actualmente, las demandas más frecuentes versan sobre expropiación o denegación de justicia.}

\subsection{El concepto de expropiación indi- recta de acuerdo con los laudos arbitrales del CIADI}

A pesar de que los tribunales arbitrales acogieron menos de la mitad de las alegaciones, ocho de los diez laudos analizados desarrollaron un concepto de expropiación indirecta, ya sea en una definición o haciendo suyo un concepto ya entregado por otros tribunales internacionales, como en el caso Santa Elena ${ }^{75}$.

Por lo general, los laudos analizados se inclinan hacia un concepto amplio de expropiación, es decir, consideran que el concepto de expropiación no implica necesariamente la transferencia del derecho

66 Robert Azinian, Kenneth Davitian y Ellen Baca v. Estados Unidos Mexicanos. CIADI Caso No ARB (AF)/97/2. Laudo, 1 noviembre de 1999.

67 Compañia del Desarrollo de Santa Elena S.A. v. Republica de Costa Rica, CIADI Caso No ARB/96/ 1. Laudo, 17 febrero de 2000. Metalclad Corporation v. Estados Unidos Mexicanos CIADI Caso No ARB(AF)/97/1, Laudo, 30 de agosto de 2000.

69 Eudoro Armando Olguin v. República de Paraguay. CIADI Caso $N^{\circ}$ ARB/98/5. Laudo 26 de julio de 2001.

70 Middle East Cement Shipping and Handling Co. S.A. v. República Arábica de Egipto. CIADI Caso No ARB/99/6. Laudo, 12 de abril de 2002.

71 Marvin Feldman v. Estados Unidos Mexicanos. CIADI Caso $N^{\circ} \mathrm{ARB}(\mathrm{AF}) / 99 / 1$. Laudo, 16 de diciembre de 2002.

72 Técnicas Medioambientales Tecmed S.A, v. Estados Unidos Mexicanos, CIADI Caso $\mathrm{N}^{\circ}$ ARB (AF)/ $00 / 2$.

73 Generation Ukraine, INC v. Ukrania. CIADI Caso No ARB/00/9. Laudo, 16 septiembre de 2003.

74 Waste Management, Inc. v. Estados Unidos Mexicanos CIADI Caso $N^{\circ}$ ARB(AF)/ 00/3. Laudo, 30 de abril de 2004.

75 En el caso Santa Elena se refirió al caso Tippets, Abbett, McCarrthy v. Tams-Affa, Laudo No. 141-72 pronunciado por el tribunal que resolvió las reclamaciones entre Estados Unidos de América e Irán. 
de propiedad, y que basta con la privación del derecho. Así lo confirma el tribunal en el caso Waste Management: «An indirect expropriation is still a taking of property. By contrast where a measure tantamount to an expropriation is alleged, there may have been no actual transfer, taking or loss of property by any person or entity, but rather an effect on property which makes formal distinctions of ownership irrelevant $\rangle^{76}$.

\section{En el caso Santa Elena se adoptó una postura más conservadora.}

El tribunal del caso Metalclad otorgó una definición bastante amplia al señalar: "expropriation under NAFTA includes not only open, deliberate and acknowledged takings of property, such as outright seizure or formal or obligatory transfer of title in favour of the host State, but also covert or incidental interference with the use of property which has the effect of depriving the owner; in whole or in significant part, of the use or reasonably-to-be-expected economic benefit of property even if not necessarily to the obvious benefit of the host State» ${ }^{77}$. Este concepto ha sido muy criticado por la amplitud de la protección del inversionista y así lo planteó la Corte Canadiense cuando conoció del caso. No obstante lo planteado, el concepto marcó una pauta para otros casos planteados ante el CIADI. Así en Middle East Cement,
Feldman y Tecmed se adoptó el mismo criterio.

Otra tendencia más conservadora en cuanto al concepto de expropiación de los tribunales CIADI fue la adoptada en el caso Santa Elena: «A property has been expropriated when the effect of the measures taken by the state has been to deprive the owner of title, possession or access to the benefit and economic use of his property" ${ }^{78}$.

Esta misma postura fue la seguida por los tribunales que resolvieron los casos Olguín y Waste Management. De lo expuesto no es posible concluir que los tribunales del CIADI hayan sido uniformes y adoptado un mismo criterio. Más bien, existen dos tendencias: una guiada por el caso Metalclad y la otra por el caso Santa Elena.

\subsection{Importancia de la finalidad de una} medida regulatoria y sus consecuencias para la expropiación indirecta

Una de las consideraciones que algunos tribunales internacionales han tomado en cuenta para determinar la procedencia de la expropiación indirecta es el rol que desempeña la finalidad de un acto de la administración del Estado. En la actualidad existen dos tendencias: un argumento es el "poder de policía (police power)» que considera el interés que lleva envuelta la medida gubernamental, la otra corriente es el «solo efecto (sole effect doctrine)», que se refiere a la ex-

\footnotetext{
76 Waste Management v. México, nota supra, par. 143.

77 Metalclad Corporation v. México, nota 68 supra, par. 103.

78 Santa Elena S.A. v. Costa Rica, nota 67 supra, par. 77.
} 
propiación en el efecto que el acto administrativo provoca en la posición de los intereses del inversionista.

\section{No existe uniformidad de criterio en las decisiones de los tribunales del CIADI.}

De los laudos del CIADI analizados, solo cinco desarrollaron esta materia. De ellos los casos Santa Elena, y Metalclad, respectivamente, sostuvieron la sole effect doctrine. En este último, el tribunal sostuvo: "where property is expropriated, even for environmental purposes, whether domestic or international, the state's obligation to pay compensation remains» ${ }^{79}$. "The Tribunal need not decide or consider the motivation or intent of the adoption of the Ecological Decree ${ }^{80}$.

Los casos Feldman, Tecmed y Tradex Hellas adoptaron la posición de police power. El primero consideró: "governments must be free to act in the broader public interest through protection of the environment... Reasonable governmental regulation of this type cannot be achieved if any business that is adversely affected may seek compensations ${ }^{81}$.

Como conclusión, no existe uniformidad de criterio en las decisiones de los tribunales del CIADI. Sin embargo, el dere- cho internacional se ha mostrado partidario de la doctrina del police powers, y así lo confirman decisiones adoptadas en las disputas entre Estados Unidos e Irán. « $A$ State is nol responsible for loss of property or for other economic disadvantage resulting from bona fide general taxation or any other action that is commonly accepted as within the police power of States, provided it is not discriminatory and is not designed to cause the alien to abandon the property to the State or to sell it at a distress price» $^{82}$.

\subsection{Expropiación indirecta en}

contraposición a privación transitoria del derecho de propiedad de una inversión extranjera

Otro criterio para determinar si hay expropiación indirecta es la duración de una medida de la administración del Estado. Solo tres de los laudos examinados se refirieron a la duración de la interferencia como una de las condiciones para determinar si el acto constituía expropiación indirecta. Como el número de casos no es muy significativo, no es posible establecer un principio. Sin embargo, podría percibirse una tendencia incipiente.

Tres de los casos analizados fueron coincidentes en sostener que para que exista expropiación indirecta es necesario que la privación sea permanente, no bastando

Metalclad Corporation v. México, nota 68 supra, par.72.

Metalclad Corporation v. México, nota 68 supra, par.111.

Marvin Feldman v. México, nota 71 supra, par. 103.

Emanuel Too v. Greater Modesto Insurance Associates, nota 49 supra, Rep. 378. 
una medida transitoria. Los casos que apoyaron esta posición fueron Metalclad, Generation Ukraine y Tecmed. En este último, el tribunal sostuvo que: «are an indirect de facto expropriation if they are irreversible and permanent and if the assets or rights subject to such measure have been affected in such a way that $)^{83}$.

\section{El momento de la expropiación}

es relevante para determinar

\section{la indemnización que debe pagar el Estado.}

En conclusión, los tribunales del CIADI han sostenido que las medidas adoptadas por los Estados que impliquen interferencias transitorias en el derecho de propiedad de un inversionista extranjero no constituyen expropiación indirecta. Esta postura concuerda con la costumbre internacional ${ }^{84}$. No obstante, los tribunales internacionales no han aplicado un criterio uniforme ${ }^{85}$.

\subsection{Determinación de la fecha de una expropiación indirecta}

El momento exacto en que se produjo la expropiación cobra relevancia al deter- minar el monto de la indemnización que debe cancelar el Estado, en caso que la demanda del inversionista sea acogida. Para establecer la fecha en que se produjo la expropiación han surgido dos tendencias, una es el momento en que se inició la interferencia, y la otra es el día en que las interferencias desembocaron en una situación de total y permanente privación.

Cuatro de las decisiones del CIADI se refirieron al momento en que se produjo la expropiación. Tres de ellas sostuvieron que el momento de la expropiación indirecta se produjo cuando la interferencia o el cúmulo de interferencias se tradujo en una total y permanente privación del derecho de propiedad. Los casos que sostuvieron esta postura fueron Santa Elena, Tecmed y Middle East. Así, en el segundo se señaló: «there is no doubt that in the future the Landfill may not be used for the activity for which it has been used in the past and that Cytrar's economic and commercial operations in the Landfill after such denial have been fully' and irrevocably destroyed, just as the benefits and profits expected or projected by the Claimant as a result of the operation of the Landfill $\rangle^{86}$.

Solo en el caso Metalclad el tribunal adoptó un criterio diferente al disponer:

Técnicas Medioambientales Tecmed S.A, v. México, nota 72 supra, par. 116.

Appleton, Barry, «Regulatory Takings: The International Law Perspective», New York University Environmental Law Journal. Vol.11.2002. p. 45. «Following the established practice of international law, both tribunals required that this harm be based on a finding of fact by the tribunal. Only «substantial» or «significant» deprivations, rather than temporary ones, seem to be recognized by tribunals as expropriations at this time. As a result of these decisions, it is clear that the customary international law understanding of expropriation has been followed by these NAFTA tribunals».

Controversias surgidas entre Estados Unidos de América e Irán, casos Motorola Inc. v. The government of the Islamic Republic of Iran et al., Laudo No. 373-481-3. (1988) y Starret Housing Corp., nota 12 stipra. Técnicas Medioambientales Tecmed S.A, v. México, nota 72 supra, par. 117. 
"The Tribunal considers that of the various possible dates at which it might be possible to fix the engagement of Mexico's responsibility, it is reasonable to select the date on which the Municipality of Guadalcazar wrongly denied Metalclad's application for a construction permit. The Tribunal therefore concludes that interest should be awarded from that date» ${ }^{87}$. Sin embargo, los principales fundamentos de la decisión del tribunal que resolvió el caso Metalclad fueron, en gran medida, anulados por la corte de revisión, la Suprema Corte de la Columbia Británica. Dicha Corte mantuvo la posición adoptada por los tribunales del CIADI.

En conclusión, la mayoría de las decisiones del CIADI han sido partidarias de que para determinar la fecha de la expropiación indirecta se debe considerar cuando la o las interferencias han conducido a una situación de total y permanente privación.

\subsection{Actos administrativos que según tribunales arbitrales del CIADI} constituyen expropiación indirecta y actos de la administración que no corresponde indemnizar

A continuación se presentarán los actos de la administración del Estado que según los tribunales del CIADI constituían expropiación indirecta y aquellos en que no correspondía indemnización.
2.5.1. Actos de la administración del Estado que constituyen expropiación indirecta

\section{La imposibilidad de continuar con un negocio se consideró expropiación indirecta.}

2.5.1.1. Anulación de licencias y permisos

Los tribunales de los casos Metalclad y Tecmed consideraron que la imposibilidad de continuar en el negocio por la no renovación de una licencia o el rechazo al otorgamiento de un permiso fueron actos constitutivos de expropiación indirecta. El segundo de ellos señaló: "the reasons that prevailed in INE's decision to deny the renewal of the Permit were reasons related to the social or political circumstances and the pressure exerted on municipal and state authorities and even on INE itself created by such circumstances $^{88}$... the Arbitral Tribunal finds and resolves that the Resolution and its effects amount to an expropriation in violation of Article 5 of the Agreement and international law ${ }^{89}$.

87 Metalclad Corporation v. México, nota 68 supra, par. 129.

88 Técnicas Medioambientales Tecmed S.A, v. México, nota 72 supra, par. 132.

89 Técnicas Medioambientales Tecmed S.A, v. México, nota 72 supra, par. 151. 


\section{Las declaraciones de autoridades de gobierno no pueden constituir por sí acto expropiatorio.}

\subsubsection{Apropiación de un derecho de propiedal}

El derecho internacional protege el derecho de propiedad de los extranjeros. En consecuencia, el acto del Estado de tomar posesión de una propiedad privada no puede considerarse acto legítimo. En el caso Middle East el tribunal concluyó que la toma del barco Poseidón 8 y su posterior subasta fueron constitutivos de un acto expropiatorio: "It is undisputed that the ship Poseidon was subjected to an administrative seizure by the Red Sea Port Authority on October 13, 1999 and then auctioned on November 2, 1999..., the Tribunal concludes that the Poseidon was taken by a 'measure the effects of which would be tantamount to expropriation' and that the Claimant is entitled to a compensation ${ }^{91}$.

\subsubsection{Otros}

Pese a que no se acogió la demanda, en el caso Feldman se individualizaron actos que según el derecho internacional han sido expropiatorios: «El Tribunal observa que son muchas las formas en que las autoridades gubernamentales pueden dejar a una empresa fuera del negocio o reducir significativamente los beneficios económicos de su actividad comercial. Antiguamente, los impuestos confiscatorios, la denegación del acceso a la infraestructura o a las materias primas necesarias o la imposición de regímenes regulatorios arbitrarios, entre otros, han sido considerados medidas expropiatorias» $)^{92}$.

2.5.2. Actos de la administración del Estado no constitutivos de expropiación indirecta

\subsubsection{Declaraciones de autoridades de gobierno}

Este tipo de actos no puede por sí constituir acto expropiatorio aunque su contenido se relaciona con una acción del gobierno y que para que lo sea se requiera la privatización de terreno. En el caso Tradex Hellas se planteó esta situación: "that speech (Mr. Sali Berisha, representante del gobierno) of 27 October 1992 emphasized to the general public that the government intended to in fact implement its privatization program also regarding agricultural enterprises. But the Berisha speech was neither a legislative or executive act nor did it change the situation found above in Section e) created by Decision 452... Therefore, the Berisha speech 
cannot be considered to be an expropriation, by itself or together with Decision $452 »^{93}$.

\section{La mala gestión en los negocios no es suficiente para considerar al Estado como responsable.}

\subsubsection{Acciones de la población}

Las acciones de la población como tomas de terreno, desórdenes en la vía pública o privada que impidan el normal desarrollo del negocio de un inversionista no constituyen expropiación indirecta pues no son atribuibles a acciones del Estado. Así lo sostuvo el tribunal que resolvió el caso Tradex Hellas: «if the villagers felt encouraged to such occupations by Decision 452 and the Berisha speech, that would not be a sufficient basis to attribute such occupations to the State of Albania» ${ }^{94}$.

\subsubsection{Mala gestión de los negocios}

La poca diligencia en la gestión de un negocio o la falta de habilidad para enfrentar una crisis económica no es motivo suficiente para considerar que el Estado es responsable de un acto expropiatorio. Los casos que se refirieron a la gestión de negocios y sostuvieron que no debía considerarse acto expropiatorio fueron Olguín, Feldman, Generation Ukraine, Waste Management y Middle East. Este último sostuvo: "To accept a claim in this regard under the BIT, the Tribunal would have to find a 'measure the effects of which would be tantamount to expropriation' (Art. 4). The provision, thus, does not cover any losses occuring to an investor due to commercial risks ${ }^{95}$.

\subsubsection{Incumplimiento de contrato}

Los tribunales señalaron que hay que distinguir entre la violación de un contrato y la violación de las obligaciones establecidas en el tratado. Los actos administrativos que involucren meras violaciones contractuales no son constitutivos de expropiación, argumentación señalada por los tribunales en las controversias Azinian y Waste Management. El tribunal en el segundo sostuvo: «El mero incumplimiento de una obligación contractual no debe ser equiparado a la confiscación de una propiedad, como tampoco (a menos que esté acompañado por otros elementos) es equivalente a una expropiación. Cualquier parte de carácter privado puede incumplir sus contratos, mientras que la nacionalización y la expropiación son actos inherentemente gubernamentales.... $\rangle^{96}$.

93 Tradex Hellas S.A. v. República de Albania, nota 65 supra, par.156 y 157.

94 Tradex Hellas S.A. v. República de Albania, nota 65 stupra, par. 165.

95 Middle East Cement Shipping and Handling Co. S.A. v. Egipto, nota 70 supra, par. 153. 


\section{Como soberano dentro de su territorio el Estado puede expropiar la propiedad de un extranjero.}

Al rechazar los tribunales del CIADI las demandas por expropiación indirecta en más de la mitad de los casos analizados, predominan en esta lista actos no indemnizables. Sin embargo, se enumeraron los actos de la administración del Estado que los tribunales consideraron actos constitutivos de expropiación indirecta.

\subsection{Consideraciones que los Estados deben tener en relación con la expropiación}

Un Estado es soberano dentro de su territorio, y en virtud de ello puede expropiar la propiedad de un extranjero. Para el Estado receptor de capital es importante determinar con exactitud su ámbito de acción y las atribuciones que puede ejercer sin violar las normas del derecho internacional. El objetivo del Estado es tener el poder de dictar normas que regulen los derechos y obligaciones de inversionistas extranjeros sin correr el riesgo de verse envueltos en instancias jurisdiccionales que involucren el pago de indemnización.

Los resguardos que los Estados podrían considerar y así prevenir futuras reclamaciones ante tribunales internacionales en casos relativos a expropiación indirecta pueden ser anteriores o posteriores a la suscripción de un tratado.

\subsubsection{Consideraciones anteriores a la suscripción de un tratado}

Después de analizar la jurisprudencia del CIADI relativa a la expropiación indirecta, surge la inquietud de si podría haberse desechado el resultado favorable al inversionista, en alguna de las controversias, si los tratados hubieran contemplado otras disposiciones en materia de expropiación indirecta.

Antes de suscribir un tratado relativo a la expropiación indirecta convendría que los Estados adoptaran algunos resguardos respecto del alcance e interpretación de las normas acordadas y del derecho aplicable a las materias no reguladas.

A continuación se presentan algunos temas que podrían ser de utilidad a un Estado, antes de que suscriba un acuerdo sobre inversiones.

\subsubsection{El concepto de expropiación indirecta}

En la aplicación e interpretación de tratados que no contemplan definiciones se han presentado varios problemas. Así, en los casos Metalclad, Feldman, Azinian - Tecmed planteados ante tribunales del CIADI por violaciones a las normas del NAFTA, los árbitros se han visto en la necesidad de establecer un concepto de la expropiación indirecta. El riesgo que ello conlleva es otorgarle al tribunal una amplia libertad de criterio, que no siempre puede ser beneficioso para el Estado.

Para evitar la discrecionalidad de los árbitros, conviene que los Estados defi- 
nan el alcance del concepto de expropiación indirecta. De hecho, los Estados Unidos de América así lo hizo al suscribir los TLC con Australia97, Chile ${ }^{98}$, Centroamérica ${ }^{99}$ y Marruecos ${ }^{100}$ incorporándoles una definición de la expropiación indirecta en los anexos respectivos.

\section{El concepto de utilidad pública es amplio y subjetivo.}

\subsubsection{Concepto de utilidad pública}

El concepto de utilidad pública es amplio y subjetivo, y tanto el Estado como el inversionista pueden tener interpretaciones diferentes según sus intereses. Sería conveniente que al negociar los tratados los Estados logren especificar las circunstancias en que hay utilidad pública. Un ejemplo de utilidad pública es que el Estado pueda ejercer sus poderes de policía. Esa postura tuvieron los Estados para evitar limitaciones a sus atribuciones.
Por esta razón, los acuerdos sobre inversiones mencionados en el punto 2.6.1.1 se han referido a expropiación indirecta y al derecho a regular: "Except in rare circumstances, nondiscriminatory regulatory actions by a Party that are designed and applied to protect legitimate public welfare objectives, such as public health, safety, and the environment, do not constitute indirect expropriations».

\subsubsection{Derecho aplicable a materias no reguladas}

Para resolver una controversia cuyo punto de discusión no ha sido contemplado en un tratado, el tribunal debe recurrir a las fuentes del derecho internacional señaladas en el artículo 38 del Estatuto de la Corte Internacional de Justicia. Existen materias relativas a expropiación que son reguladas por normas consuetudinarias, tales como la doctrina sobre el «poder de policía» ${ }^{101}$ y la no discriminación ${ }^{102}$.

Hay otras materias respecto de las

97 Acuerdo de Libre Comercio Estados Unidos-Australia, firmado el 1 de marzo de 2004, Anexo 1 1-B, Articulo 4(b).

98 Acuerdo de Libre Comercio Estados Unidos-Chile, firmado el 6 de junio de 2003, Anexo 10-D.

99 Acuerdo de Libre Comercio Estados Unidos-Centroamérica (CAFTA) firmado el 28 de enero de 2004, Anexo 10-C. Los países Centroamericanos son: Costa Rica, El Salvador, Guatemala, Honduras, Nicaragua.

100 Acuerdo de Libre Comercio Estados Unidos-Marruecos, firmado el 15 de junio de 2004, anexo 10-B.

101 Marvin Roy Feldman Karpa (CEMSA) v. México, nota 71 supra, par. 103. El tribunal sostuvo: «governments must be free to act in the broader public interest through protection of the environment, new or modified tax regimes, the granting or withdrawal of government subsidies, reductions or increases in tariff levels, imposition of zoning restrictions and the like. Reasonable governmental regulation of this type cannot be achieved if any business that is adversely affected may seek compensation, and it is safe to say that customary international law recognizes this».

102 Es un principio generalmente aceptado como costumbre internacional que en los casos en que se produzcan perjuicios económicos producto de una regulación de buena fe y en el ejercicio de sus atribuciones de poder de policia, la indemnización no es obligatoria. Una medida será discriminatoria si 
cuales no existe claridad en el derecho internacional y, por tanto, no hay costumbre internacional que supla aquellas materias no reguladas en un tratado. Siendo así, convendría que los negociadores contemplaran necesariamente en el tratado disposiciones sobre temas relativos a desde cuándo se paga interés y si este es simple o compuesto ${ }^{103}$ o qué normas son aplicables al debido proceso en una expropiación ${ }^{104}$.

\section{Los Estados deben tomar precauciones para no perjudicar intereses de inversionistas extranjeros.}

La importancia de estas especificaciones se refleja en el caso Middle East en el cual el tratado no contemplaba el tipo de interés. El tribunal aplicó el interés compuesto incrementando en forma sustancial el monto de la compensación: «The Tribunal considers that the provision in Egyptian law on which Respondent relies is not applicable to claims based on the BIT, i.e., public international law. The BIT provides (Art. 4.c)) that the compensation in case of expropriation "shall include interest until the date of payment.» Regarding such claims for expropriation, international jurisprudence and literature have recently, after detailed consideration, concluded that interest is an integral part of the compensation due after the award and that compound (as opposed to simple) interest is at present deemed appropriate as the standard of international law in such expropriation cases» ${ }^{105}$.

\subsubsection{Resguardos posteriores a la sus- cripción de un tratado}

Una vez que el tratado haya entrado en vigor, cualquier violación atribuible al Estado, constituye a este en responsable ante al derecho internacional. En consecuencia, los Estados deben tomar todas las precauciones para no perjudicar los intereses de un inversionista extranjero y cuyos actos pudieren ser constitutivos de expropiación indirecta.

su resultado es: «an actual injury to the alien... with the intention to harm the aggrieved alien» to favour national companies. Ver Dolzer and Stevens, Bilateral Investment Treaties, CIADI. 1995. El tribunal Iran-US en el caso Amoco reconoce: «discrimination is widely prohibited by customary international law in the field of expropriation», aunque no encontró que en este caso hubiera discriminación.

Algunos tratados consideran que la indemnización comprende desde la fecha de la expropiación, pero la mayoría de los APPI no se refieren al tema. El APPI Noruega-Hungría de 1991, establece en el articulo VI: "Such compensation shall amount to the market value of the investment immediatly befote the date of expropriation and shall be paid without delay and shall carry an annual rate of interest equal to 12 months libor quoted for the currency in which the investment was made until the time of payment». general lack of references to domestic law reflects the very purpose of the BIT».

105 Middle East Cement Shipping and Handling Co. S.A. v. Egipto, nota 70 supra, par. 174. 


\subsubsection{Incompatibilidad entre las disposiciones del tratado y la} normativa nacional

Uno de los primeros resguardos que debe tener un Estado es conocer qué disposiciones del tratado son incompatibles con la normativa nacional. El Estado debería lograr armonizar sus normas nacionales antes de que el tratado entre en vigor, para así evitar discrepancias que puedan llevar a que un inversionista extranjero se vea afectado en su derecho de propiedad.

Los problemas que se plantean en la armonización de legislaciones es la posible diferencia de estándares en el tratamiento de la expropiación contemplado en el tratado y en el derecho interno. En este caso, el Estado se verá obligado a modificar su regulación interna para no incurrir en violación de los derechos de propiedad de un inversionista extranjero. Las regulaciones, medidas o actos de la administración del Estado que no estén en consonancia con los tratados suscritos, pueden ser la base de una demanda ante el CIADI por expropiación indirecta.

\subsubsection{Mayor control de los organis- mos dependientes del Estado}

De acuerdo con las normas que rigen la responsabilidad, los Estados son responsables por los actos de los gobiernos provinciales que se encuentren dentro de su territorio ${ }^{106}$. Por ejemplo el Nafta establece que: "[t]he Parties shall ensure that all necessary measures are taken in order to give effect to the provisions of this Agreement, including their observance, except as otherwise provided in this Agreement, by state and provincial governments» ${ }^{107}$.

\section{Los Estados responden por los actos de los gobiernos provinciales.}

La mitad de los casos analizados planteados ante el CIADI en que se acogieron las demandas por expropiación correspondieron a actos de órganos dependientes del Estado. En el caso Metalclad, el tribunal consideró que los actos del municipio fueron atribuibles al gobierno mexicano y, en virtud de ello, este era económicamente responsable por la expropiación indirecta: «Mexico's international

106 En el caso Metalclad el tribunal en par. 73 sostuvo: «Este enfoque está en total acuerdo con el derecho internacional consuetudinario. Esto se expresó claramente en el artículo 10 del proyecto de artículos sobre responsabilidad de los Estados adoptado por la Comisión de Naciones Unidas de Derecho Internacional en 1975 que, aunque está todavía en discusión, puede, aun así, considerarse como una correcta reafirmación del derecho actual: [e]l comportamiento de un órgano del Estado, de una entidad territorial del gobierno o de una entidad facultada para ejercer atribuciones del poder público, cuando tal órgano ha actuado en esa calidad, se considerará como un acto del Estado según el derecho internacional aunque, en el caso de que se trate, el órgano se haya excedido en sus atribuciones de conformidad con el derecho interno o haya contravenido las instrucciones concernientes a su ejercicion (Yearbook of the International Law Commission, 1975, vol. ii, p. 61).

107 NAFTA, 1992. Artículo 105. 
responsibility is founded upon an accumulation of a number of factors. In the circumstances, the Tribunal considers that of the various possible dates at which it might be possible to fix the engagement of Mexico's responsability, it is reasonable to select the date on which the Municipality of Guadal-cazar wrongly denied Metalclad's application for a construction permit»l${ }^{108}$.

\section{En la actualidad, la expropiación es el punto más controversial en} derecho internacional.

Los municipios, ministerios u otras entidades tienen mucha interacción con los inversionistas extranjeros en lo que se refiere a la autorización o prórroga de permisos y licencias para llevar a cabo su proyecto. Por tanto, una decisión u acto ilegal o arbitrario de alguna de las reparticiones del Estado puede implicar el riesgo de tener que pagar cuantiosas indemnizaciones a inversionistas extranjeros y a desembolsar grandes sumas para la defensa jurídica ante un tribunal internacional.

\section{CONCLUSIÓN}

No existe discusión en cuanto a que el derecho internacional protege la propiedad tangible e intangible de un extranjero. Sin embargo, actualmente el punto controvertido es el ámbito de la expropia- ción, no aquella que transfiere el título de propiedad, sino la que constituye expropiación indirecta. La razón del problema radica en lo complejo de ubicar la línea divisoria entre las medidas reguladoras legítimas de aquellos actos que sí se consideran interferencias ilegítimas en los derechos e intereses de un inversionista extranjero y que tienen como resultado una expropiación indirecta.

La mayoría de la APPI contiene disposiciones vagas respecto de las obligaciones de un Estado cuando este es responsable de expropiación. Más aún, no hay costumbre internacional que resuelva estos puntos no resueltos por los tratados. Por otro lado, durante casi un siglo los tribunales internacionales han desarrollado mayores conocimientos y experiencia sobre 1o que implica la expropiación indirecta. Sin embargo, no hay distinción clara entre los actos de la administración del Estado por los cuales no corresponde pago de indemnización y otros que si constituyen expropiación indirecta y requieren indemnización.

Los objetivos de este estudio son comprender mejor la expropiación indirecta ante el derecho internacional, y lograr que este sea una guía de autorregulación de los actos administrativos de los Estados en su actuar frente a la inversión extranjera. Para lograr dicho propósito se identifican criterios comunes y nuevas tendencias de diez laudos arbitrales del CIADI en materia de expropiación indirecta, tribunal que es uno de los más importantes foros para solucionar conflictos entre inversionistas extranjeros y Estados.

108 Metalclad Corporation v. México, nota 68 supra, par. 128. 
El primer criterio analizado es el concepto de expropiación. Los tribunales se inclinaron por un concepto amplio, es decir, que no se requiere transferencia del derecho de propiedad, y basta con la privación del derecho. No obstante, no existe un criterio uniforme respecto del concepto de expropiación indirecta. Los tribunales del CIADI muestran dos tendencias: la primera, cuyo caso más representativo es Metalclad, y la segunda, el caso Santa Elena. El primero dio un concepto amplio al incluir en él la interferencia disimulada o incidental en el uso de la propiedad, que tenga por consecuencia privar significativamente al propietario del uso o del beneficio económico que razonablemente esperaría de la propiedad. En cambio, el caso Santa Elena dio una definición más conservadora, siguiendo el concepto tradicional del derecho internacional al señalar que hay expropiación indirecta cuando el efecto de las medidas tomadas por un Estado privan al propietario del título, posesión o acceso a los beneficios y uso económico de la propiedad

Una segunda consideración para determinar la procedencia de la expropiación indirecta es el rol que desempeña el propósito de un acto de la administración del Estado. Una tendencia es la «doctrina del poder de policía», que plantea que las medidas del Estado se justifican por el objetivo que persiguen, y siendo así, no existiría responsabilidad del Estado de pagar indemnización cuando actúa en virtud de ese objetivo. Este criterio es el que sigue el derecho internacional. La otra tendencia, la «doctrina del solo efecto» se centra en el efecto que la medida admi- nistrativa causa en los intereses del inversionista, sin considerar su finalidad; por tanto, si hay perjuicio siempre es indemnizable. En tribunales del CIADI se observa, el mismo conflicto pues no hay criterio uniforme al respecto. Así, en algunos casos se reconoce que los gobiernos tienen el derecho a proteger mediante acciones no discriminatorias, el ambiente, la salud y la seguridad humana, la integridad del mercado y las políticas sociales. Todo ello sin la obligación de pagar una indemnización, aunque exista privación incidental en la propiedad de un extranjero. Por el contrario, en otros casos consideró que lo importante es determinar la expropiación indirecta a partir de su efecto en la inversión extranjera.

\section{Los tribunales adoptaron un concepto amplio de expropiación.}

La tercera materia analizada es la determinación de la expropiación indirecta de acuerdo con la duración de la medida administrativa que afecta al derecho de propiedad. En todos los casos en que se discutió este punto, los tribunales concordaron que para que exista expropiación indirecta es necesario que la privación del derecho de propiedad sea permanente. Es decir, las medidas del Estado que implican interferencia transitoria del derecho de propiedad de un inversionista extranjero no constituyen expropiación indirecta. Esta posición concuerda con la costumbre internacional.

El cuarto aspecto analizado es la determinación de la fecha de la expropia- 
ción indirecta. Una tendencia considera que se cuenta desde el momento en que se produce la interferencia. Por el contrario, otra tendencia se funda en que la expropiación se inicia cuando la interferencia condujo a una situación de privación total y permanente de los derechos del inversionista. La mayoría de las decisiones de los tribunales del CIADI optaron por el criterio de que comienza cuando la interferencia o las interferencias condujeron a una situación de privación total y permanente.

\section{Convendría que los Estados definieran el alcance de la expropiación indirecta.}

El quinto punto analizado se refiere a qué actos administrativos se consideran expropiación indirecta. Los tribunales señalaron que constituyen esta clase de expropiación las decisiones administrativas que anulan licencias y permisos y la confiscación de bienes. Los tribunales, a su vez, indicaron qué actos no se consideran expropiatorios a pesar de perjudicar los intereses de los inversionistas, como son declaraciones de autoridades del gobierno, acciones de la población, mala gestión de negocios y violación de un contrato.

Otro gran tema dentro de este estudio son las actuales tendencias y medidas que pueden tomar los Estados para evitar posibles controversias sobre expropiación indirecta. Ellas pueden ser anteriores o posteriores a la suscripción de un tratado.

Las precauciones que pueden adoptar los Estados antes de suscribir un acuerdo en materia de inversiones se orientan a establecer con claridad y precisión el alcance de sus cláusulas. Al respecto, convendría que los Estados definan con exactitud el alcance del concepto de expropiación indirecta, especifiquen las circunstancias en que los Estados pueden actuar en virtud de su poder de policía e indiquen qué se entiende por utilidad pública. Recientemente, la nueva generación de acuerdos de inversión, incluyendo los capítulos sobre inversión de los acuerdos de libre comercio, ha introducido disposiciones y criterios específicos para determinar si ha ocurrido una expropiación indirecta que requiera pago de indemnización. Estos resguardos tienden a evitar la discrecionalidad de los arbitradores. Además, hay otros temas relacionados con la expropiación que no están bastante claros en derecho internacional. Por consiguiente, es recomendable que los negociadores incluyan especificaciones sobre el momento en que deban pagarse los intereses si estos deben ser simples o compuestos.

Los resguardos que puede adoptar un Estado después de haber suscrito un tratado se relacionan, primero con las cláusulas del tratado que pudieran resultar incompatibles con las regulaciones nacionales y segundo, con el ejercicio del control ejercido por el Estado sobre sus diversas reparticiones. Una de las primeras precauciones que un Estado debe adoptar al firmar un tratado es determinar previamente las normas legales que entrarían en conflicto. Un Estado debe subsanar las posibles discrepancias para evitar que los intereses de los inversionistas se vean afectados cuando el tratado entre en vigor. 
La segunda precaución es ejercer un adecuado control sobre los organismos dependientes del Estado. Un acto ilegal o una decisión arbitraria de un órgano pueden desencadenar un serio problema internacional y llegar a provocar un grave daño patrimonial del Estado. Por esta razón, deberían concebirse mecanismos de supervisión más eficientes.

\section{BiBLIOGRAFİA}

Appleton, Barry, «Regulatory Takings: The International Law Perspective», New York University Environmental Law Journal, Vol. 11, 2002, pp. 35-48.

American Law Institute, Restatement (Third) of the Foreign Relations Law of the United States, American Law Institute Publishers, Washington, 1987.

Blackaby, Nigel, «El arbitraje según los tratados bilaterales de inversión y tratados de libre comercio de América Latina», Revista Internacional de Arbitraje, $\mathrm{N}^{\circ} 7,2004$, pp.17-63.

Brownlie, Ian, Public International Law, Oxford, Oxford University Press, $6^{3}$ edición, 2003.

Brunetti, Maurizio, «Indirect Expropriation in International Law, Recurring Themes», International Law Fortun du droit international, Vol. 5, 2003, pp.150-154.

CIADI cases, disponible en <hhttp:// wwwworldbank.org/CIADI/cases/awards.htm>.

Comeaux, Paul E. y Kinsella N. Stephan, Protecting Foreign Investment Under Internacional Law: Legal Aspects of Political Risk, Nueva York, Oceana Publications Inc., 1997.

Christie, G.C., "What Constitutes a Taking of Property Under International Law?», British YearBook of International Law, Vol.38, 1962, pp. 307-338.

Dolzer, Rudolf, «Indirect Expropriation of Alien Property», Foreign Investment Lan Joumal, Vol. 1, No 1, 1986, pp.41-65.

——, «Indirect Expropriations: New
Developments?», N.Y.U. Environmental Law Jouma, Vol. 11, 2002, pp. 64-93.

__ y Bloch, Felix, «Indirect Expropriation: Conceptual Realignments?», International Law Fortum, Vol. 5, 2003, pp. 155-165.

y Stevens, Margrete, Bilateral Investment Treaties, Washington, CIADI, 1995.

Enriquez, Raymundo E., "Expropriation under Mexican Law and its Insertion into A Global Context Under NAFTA», Hastings International and Comparative Law Review, Vol. 23, 1999-2000, pp. 385-392.

Fridh, Hilda y Jensen, Olivia, «Investor-to-State Dispute Settlement: What can we learn?», Centre for Competition Investement \& Economic Regulation, $\mathrm{N}^{\circ} 7,2003$.

Garcia-Amador, F. V., «The Changing Law of The International Claims», Oceana Publications, INC., Nueva York, Volumen 1, pp.278-288.

Heiskanen, Veijo, «The Contribution of The IranUnited States Claims Tribunal to the Development of the Doctrine of Indirect Expropriation', International Law Fortm, Vol. 5, No 3, 2003, pp. 176-187.

Higgins, Rosalyn, «The Taking of Property By the State: Recent Developments in International Law', Recueil des Cours, Vol. 176, 1982, pp. 259-389.

Khalaf Masa'Deh, Ahmad, «International Rules for Investment and Investors: Light at the End of the Tunnel?", European Business Law Review, 2000, pp. 157-178.

Lowe, Vaughan, «Regulation or Expropriation?», Current Legal Problems, Vol. 55, 2002, pp. 447-466.

Madalena, Ignacio, «Foreign Direct Investment and the Protection of the Environment: the Border Between National Environmental Regulation and Expropriation', European Environmental Law Review, Vol. 12, №3, 2003, pp. 70-82.

Mouri, Allahyar, The International Law of Expropriation as Reflected in the Work of the Iran-U.S. Claims Tribunal, Dordrecht, Martinus Nijhoff Publishers, 1994.

Organisation for Economic Cooperation and Development, Draft Convention on the Protection of Foreign Property, Paris, O.E.C.D. Publications, 1962.

Orrego Vicuña, Francisco, «Carlos Calvo, Honorary 
Nafta Citizen», N.Y.U. Environmental Law Journal, Vol. 11, 2002, pp. 19-34.

, «Regulatory Authority and Legitimate Expectations: Balancing the Rights of the State and the Individual under Internationaly, International Law FORUM du droit international, Vol. 5, $\mathrm{N}^{\circ} 3,2003$, pp. 188197.

Piran, Hossein, «Indirect Expropriation in the Case Law of the Iran-United States Claims Tribu- nal», The Finnish Yearbook of International Law, Vol. 6, 1995, pp. 140-247.

Porterfield, Matthew $\mathrm{C}$., «International Expropiation Rules and Federalismus, Stanford Environmental Law Jounal, Vol. 23, 2004.

Sorensen, Max, Manual de Derecho Internacional Píblico, México, Fondo de Cultura Económica, 2004, pp. 507-568.

Sornarajah, M., The International Law of Foreign Investment, Cambridge, Cambridge University Press, 1994. 